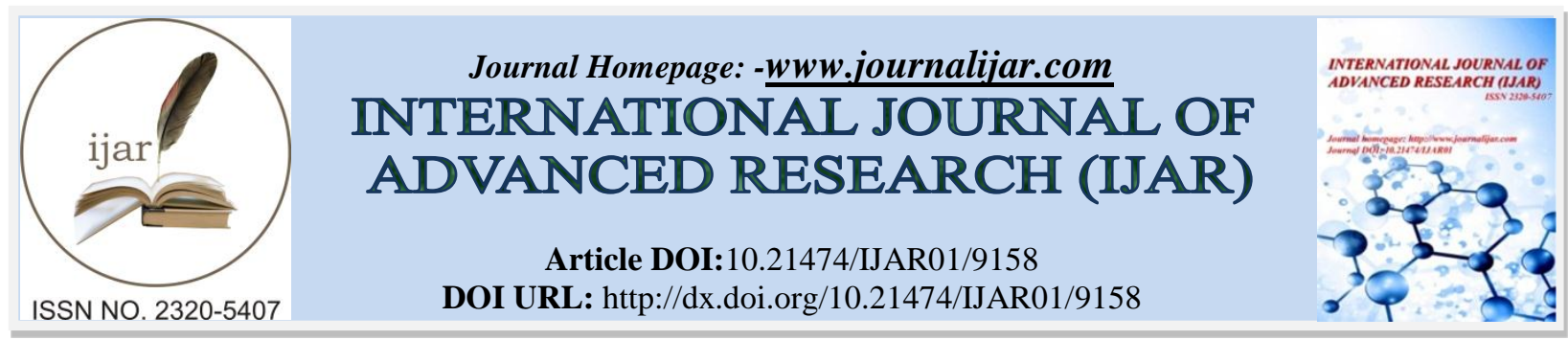

RESEARCH ARTICLE

\title{
A CRITICAL REVIEW OF THE VARIOUS HUMAN RESOURCE MANAGEMENT PRACTICES, MODELS AND THEIR APPLICATION IN HIGHER EDUCATIONAL INSTITUTION.
}

Sabah Javed ${ }^{1}$, Prof. Naseem Ahmed ${ }^{2}$ And Dr. Darakhshan Anjum ${ }^{3}$.

1. Research Scholar, School of Management Studies, Baba Ghulam Shah Badshah University, Rajouri, Jammu and Kashmir, India.

2. Dean, School of Management Studies, Baba Ghulam Shah Badshah University, Rajouri, Jammu and Kashmir, India.

3. Assistant professor, School of Management Studies, Baba Ghulam Shah Badshah University, Rajouri, Jammu and Kashmir, India.

\section{Manuscript Info}

Manuscript History

Received: 24 March 2019

Final Accepted: 26 April 2019

Published: May 2019

\section{Key words:-}

Human resource management practices, HRM models, higher educational institutions.

\begin{abstract}
Human resource is one of the most influential factors for any economy to flourish and attain heights of development. Many researches have been conducted on human resource management (HRM) practices at different levels and it has been the field of interest for academics for several decades. Development and advancement of industries and innovative practices has empowered the organizations to retain and utilize the human resource successfully. The main intention of the study is to underline the significance of human resource management practices and their applications in higher educational institutions and to identify the research gaps. Higher education sector as evident from the published literature, plays a vital role in developing the nation as a whole. Such educational institutions have responsibility of catering to all sectors of the society may it be government or private or nongovernmental organizations. This study elucidated the significant dimensions of the HRM models in mapping the human resource as a cardinal factor in successful higher educational system.
\end{abstract}

Copy Right, IJAR, 2019,. All rights reserved.

\section{Introduction:-}

In present scenario, organizations have been enduring a difficult phase so as to sustain long in the global economy; therefore, are subjected to enormous pressure, greater challenges so as to continue their distinctiveness in an unstable and unpredictable environment. This sequentially has a massive consequence on the individuals who administrate these organizations in high degree of uncertainty relating to their physical, social and psychological unit. It turns out to be indispensable and actually, a primary responsibility of organizations to retain their employees, motivate them and maintain their high spirits in order to perform authoritatively. Organizations are conscious about the fact that the human resources are the assets to any organization and also a unique aspect which can take organization to top or vice versa. Thus, the organizations as a whole, have understood the detail that to develop and generate a milieu for themselves and be a front-runner in the prevailing competitive area, it is more significant to ease growth and development of the employees through presence of better human resource management practices.

Corresponding Author:-Sabah Javed.

Address:-Research Scholar, School of Management Studies, Baba Ghulam Shah Badshah University, Rajouri, Jammu and Kashmir, India. 
Human resource management (HRM) refers to the strategies, practices, and organizational structure that tends to have a great influence on workers' performance, opinions, and enactment. It can also be defined as a strategic, integrated and coherent approach to the employment, development and well-being of the employees working in an organization. HRM practices help to improve output through changes in employee relationships. Tzafrir \& Gur (2007) argue that Human resource management practices plays a significant role on perception of employees and their satisfaction. As per Legge (1995), human resources are the most valuable resources and it is the "human" viz. basic root of competitive edge. Bontis (1999), say that human resource can be technologically advanced at any phase as they are proficient to acquire new things, modification with period, are approachable to changes, pioneering and provides assistance in supporting the organization in the long run.

As rightly mentioned by Clothier and Spriegel (2007), Human Resource Management (HRM) is a forerunner to maintain harmony amongst employees working together in an organization and emphases on building up the relationship, in addition, provides more attention on development and growth by integrating organizational goals coordinated with individual goals. It can be contended on the basic research conducted by Noe (2011) that HRM is a structure specifically based on combination of strategies, actions and practices that considerably have influence on employee behavior, attitudes, and performance in the organization. HRM has been mentioned to include individuals and most of the organizations otherwise term it as "people practices". Schuler and Jackson (1987) it was claimed that application and usage of HRM practices as a system performs a vital function i.e., to attract, develop, motivate and retain employees and in its turn, assists in existence and provisions of the organization and its staffs in the long run. Many other academicians claimed that "Human resource management practices need to aid its fundamental hypothesis and also, take care of the organization's business policies, job design, human resource planning, recruiting, selection, training and development, potential appraisal, performance appraisal, wage and salary administration, employee communication, employee coordination and relations. HRM practices and methods that has been implemented and executed by organizations in step with human resources has an important and positive influence on o0rganizational performance extensively (Delery, 1998). All organizations can succeed only when these basic assumptions of HRM practices are implemented and performed in a strategic and effective manner. It has been showed to the organizations through various researches that, "With the better implementation of HRM practices, their employees inclined to be more jubilant and perform more effectively.

The achievement of any educational organization is supposed to depend largely on the quality of its human resources and its concern towards human resource management as the heart of the educational management (Jones \& Walters, 1994). Focusing on the milieu of higher education which has turns out to be more viable and exposed for market-driven decision making, human resources are the most influential resources that an institution could own to befit in this competitive situation and to go well with the modern entrepreneurial standard. Human resource management performs a significant role of interpreting organizational strategic objectives into human resource strategies and then, generating human resource strategies that could achieve better competitive edge (Tyson, 1997). Higher education sector as is obvious from the researches that had been conducted previously, play a fundamental role in emerging the nation entirely. Whether it is government or private or non-governmental organizations, higher educational institutions have accountability of organizing to all sectors of the society. The responsibility of the higher educational institutions is to bring into being knowledgeable and experienced individuals. Therefore, the teachers and the non-teaching staff of higher educational institutions as apparent are mainstay to the economy of the country. As they are regarded as the most important and essential resource of the society are significant contributors to socio-economic development. Nongmaithem and Biniam (2006) conducted a research study on organizational performance and HRM practices on teaching and non-teaching staff in university and he discovered that HRM practices have a significant and positive impact on the employee's performance, while allotting their roles and responsibilities towards the society. Jaskiene (2015), has concluded that there is an impact on employee's performance in which emphasis is on research and the study has also shown that HRM practices eases individual research efficiency. This reveals that HRM practices lead to better employee's performance that resulted to overall organizational effectiveness. Akram et al. (2016) determined that there is a direct and significant relationship between HRM practices that are recruitment and selection, training and development, compensation and incentives, performance appraisal and the performance of the employees and therefore, HRM practices should be technologically advanced to intensify the success and permanency of higher education institutions.

This research emphases on the human resource management practices in higher education institution as the rudimentary component to improve the quality of higher education sector, which is regarded as an important aspect for social, scientific, technological, economic, political development of nations. Basically, this research focuses on 
the models of human resource management in higher education and examines the existing realization of this model in higher education institution, related to the applied practices and the level of significance for each practice.

\section{Need For The Present Study}

Higher educational institutions in India plays a pivotal role in offering human resources to entire business and nonbusiness community. Therefore, employees working in higher education institutions need to be supported by the management so as to perform efficiently and effectively. In order to make system more effective a need arises to understand prevailing HRM practices in government and private higher educational learning institutions in the state of Uttar Pradesh. Also, the thorough literature survey unveils the fact that HRM practices and employee's performance are linked and it has always been a concern for researchers. Further, the studies reveal the better HRM practices improves organizational effectiveness hence its performance at large. But as lots of studies have been conducted on the subject in question but not much has been done in the area when it comes to higher education in the state of Uttar Pradesh, India. Additionally, a need also arises to examine the existing human resource management practices being offered and how it is being perceived by the employees of the institution. Further, acknowledging the importance of HRM practices, the present study shall focus on examining the prevailing HRM practices in the select higher educational institutions of the State and the outcome of the study will help to understand the existing human resource practices prevalent in the select higher educational institutions of the State and also to study various models of HRM and their significance. It will also help the policy makers to understand the prevailing education system in the state and shall help them improve the system further.

\section{Structure Of The Study}

Many theoretical foundations for the human resource management practices have been introduced. Management discipline are vast and flourishing, with regards to the literature that has been provided by the various eminent researchers occasionally. There has been continues up stage in the classification of human resource management practices, models and their applications in order to suit the scopes of human resource management from time to time. Although most HRM models provide no clear focus for any test of the HRM- performance link, the models tend to assume that an alignment between business strategy and HR strategy will improve organizational performance and competitiveness.

With the modification in HRM, the following factors seem to play a serious role for the comparative assessments of the human resource management practices and its dimensions:

1. human resource management is affected by the number of factors depending upon the setting in which it is to be implemented, thus recognizing those factors are a major challenge.

2. The criteria for development of human resource management practices in various.

3. The dynamic and yet important link between concepts of human resource management practices and employee's performance and ways of their evaluation.

Through the research paper an attempt is made to revisit the most widely applied models of human resource management and suggest appropriate ways for improvements of human resource management practices in the organizations.

\section{Human Resource Management Models and Theories}

Generally, the major features of HRM is well explained and demonstrated through various models proposed by different authors/ researchers from time to time. These models provide fundamental understanding of the human resource management concept which forms the base for the present theoretical study and provide individuality to HRM practices. It covers all the human resource activities effectively and efficiently which results in an experienced and enthusiastic staff who are willing to achieve organizational goals. Environment, being an utmost variable in human resource management models' states that the human resource management cannot be activated in a void manner. With the help of these models a basic understanding of HRM concept has been formed.

The theoretical perspective on HRM models are:

1. It makes available a logical outline to review HRM

2. Genuine HRM practices.

3. Establish variables and relationship that has to be researched.

4. Qualities and importance of main HR practices should be clearly outlined. 
There are some of the models of HRM, that are:

Matching model of Fombrun, Tichy and Devanna

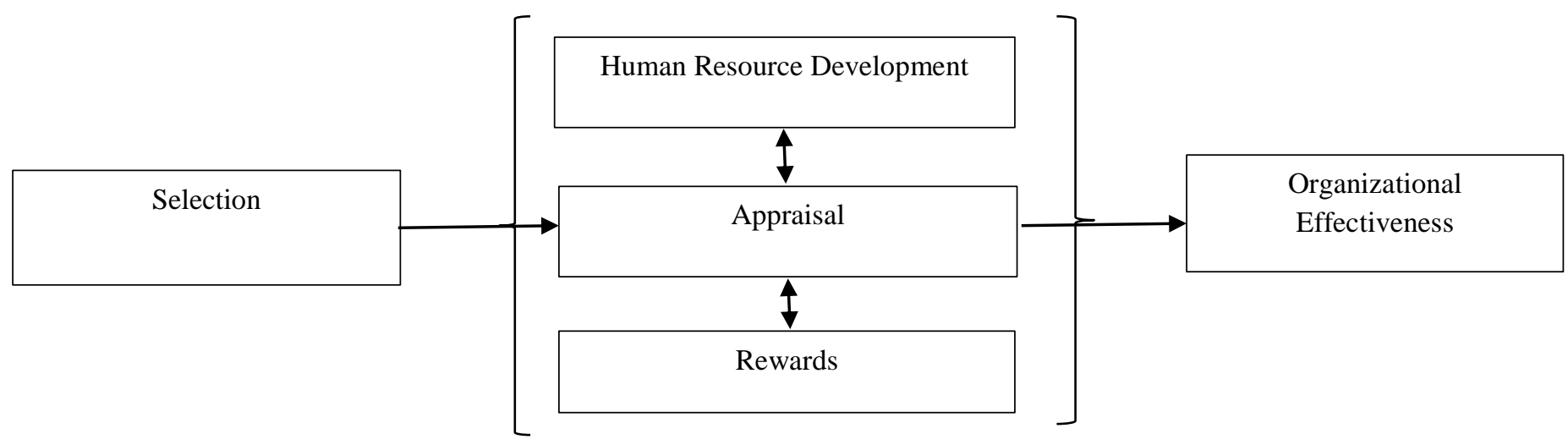

Source: Neha (2015). HR Knowledge. Adapted from:

http://nehaspeakshr.blogspot.com/2015/07/models-of-human-resource-management.html

Fombrun Tichy and Devanna (1984) aimed to proposed a model i.e., the Michigan model at the Michigan Business School. This model also called as a matching model of HRM. This matching model falls under the harder side of HRM i.e. the hard approach of HRM because it underlined more on the close relationship between HR strategy and business strategy. This is the first and very simple HRM model (dates back to 1984), which highlights four functions and their interrelatedness. The four functions of management are Recruitment and Selection, Performance Appraisal, Training and Development and Compensation/rewards. These four basic components of human resource management are considered as an important factor for the growth and development of organization. Though, this HRM model neglect other environmental factors and unforeseen event that have a direct impact on various HRM aspects. Therefore, this matching model of HRM indicated that human resource system and organizational structure are expected to be systematized in a manner that it is well-adjusted with the organizational plans and policies.

\section{Applications of the model:}

The Michigan model (Devanna et al. 1984) emphases on the hard aspects of HRM and connection with HRM activities. It embraces that human resources should be administered like any other resources i.e., obtained inexpensively, utilized economically, developed and demoralized copiously. According to this model, selection, appraisal, development and rewards were prepared to enhance the organizational performance. This model gives a clear understanding as to how an effective human resource system and institutional structure leads to the overall improvement of the institutional strategy. The model makes it clear for the employees that it is through the proper human resource system and organizational strategy only that the overall image of the institution can be improved.

\section{Limitations of the model:}

This model is inadequate as it focuses only on few functions of the HRM and ignores the other aspects of the human resource functions. The model fails to give a clear understanding as to how to measure the human resource system in the institution. The model is not comprehensive i.e., it does not cover all the aspects of human resource system in all the business setups or organizations. 


\section{The Harvard Model}

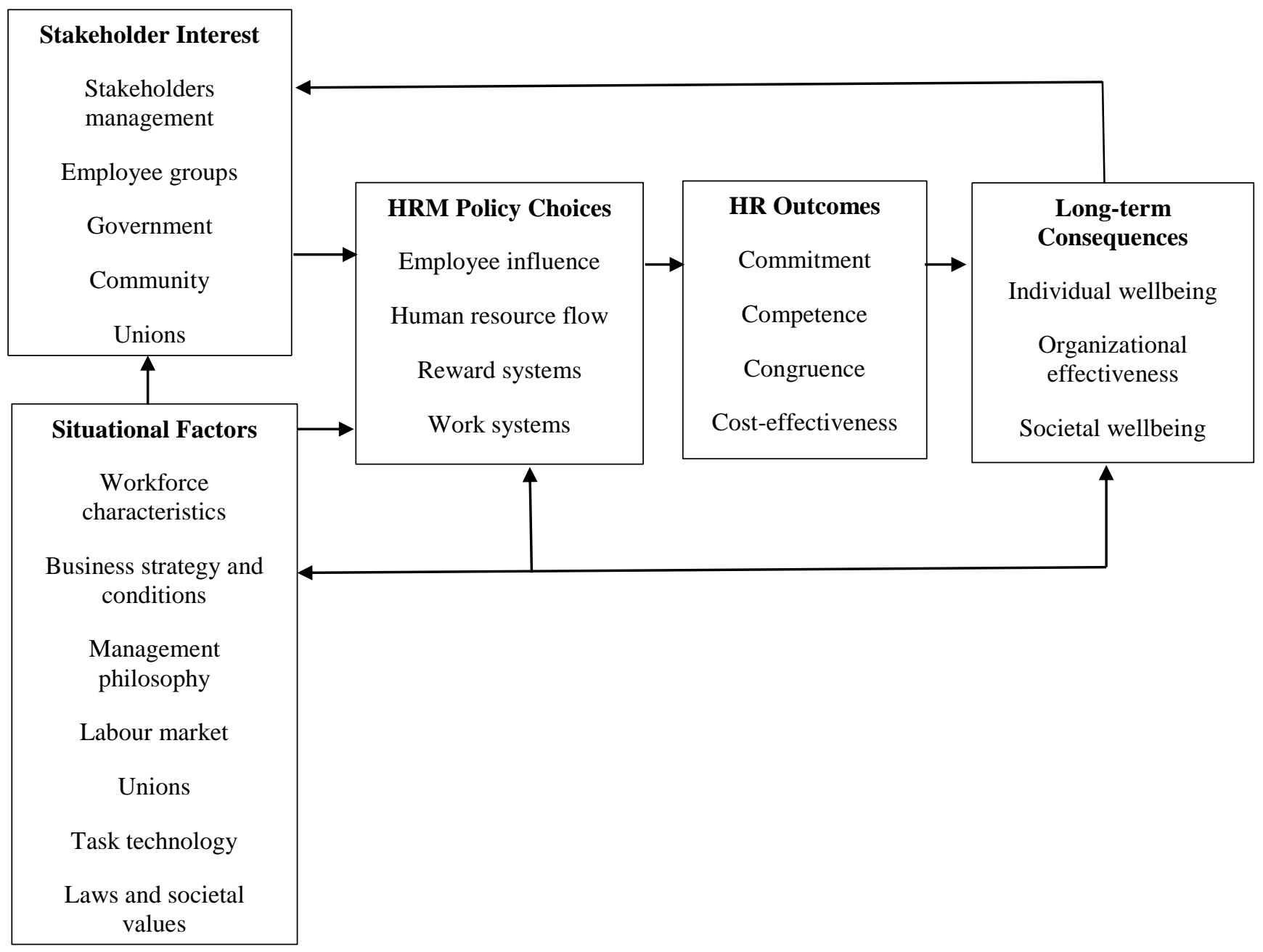

Source: Surendra Jagwan. Models of Human Resource Management. Adapted from: https://professionalshiksha.blogspot.com/2015/10/models-of-human-resource-management.html

The Harvard Model was suggested by Beer et al. (1984) at the University of Harvard. The Harvard model emphasizes on HRM extensively as it endeavors to recognize six significant parts of HRM. The model has a large scope in the matter of stockholders' interests, situational aspects, adoption of HRM strategy, HR consequences, lasting effects and a feedback loop. The productivity flow towards the organization and to the shareholders part.

The Stockholders interests shows the tradeoffs between interest groups which acts as a challenge for the HR managers to balance the interests of all stakeholders. It also recognizes the value of 'trade offs' among the owner's interests as well as the employees.

The Situational aspects comprises of dependent factors that are employees' traits, set of beliefs in a management position, market place, mission, technology, rules and regulations and societal standards. It also effects the HR strategy on the choice of management.

Adoption of HRM Strategy highlights the management's choices and activities concerning HRM, which can be completely valued only if it is known that it provides outcomes from a relationship between constraints and choices. This model plans four topics of HR Strategy: 
1. Employee Influence - delegation of authority, accountability, control etc.

2. HR Issues - recruitment and selection, upgrading, performance appraisal, dissolution etc.

3. Compensation System - salary system, incentive etc.

4. Labor System - work design and positioning of individuals.

Adoption of these four HR strategies give rise to 4 Cs of consequences to HR Strategy, that are expected to be accomplished:

1. Commitment

2. Congruence

3. Competence

4. Cost Effectiveness

Long term Consequences or Lasting effect was recommended by Beer et al. (1984), in which both profits/gains and expenses of HR strategies should be evaluated in three steps: Individual, Organizational and Societal and sequentially, examined by $4 \mathrm{Cs}$ of consequences to HR strategy.

The sixth and the final constituent is the Feedback Loop. Similarly, as situational aspects have an effect on HRM strategy and selections, and are shaped by lasting consequences. Likewise, shareholders' interests' have a great influence on the adoption of HRM strategy, and repeatedly, affected by long-term consequences.

\section{Applications of the model:}

The Harvard model emphases on the soft aspect of HRM and it works as a strategic map to guide all managers in their relations with employees. It strives at employee commitment not control. It also works on the evidence that employees needed to be congruent, competent and cost effective.

\section{Limitations of the model:}

The model is not clear as on the various exploratory factors. The model further fails to gives a better understating as to how the gaps are to be measured at the different levels. Further the model is not clear about the identification of human resource system for the management.

\section{The Guest Model}

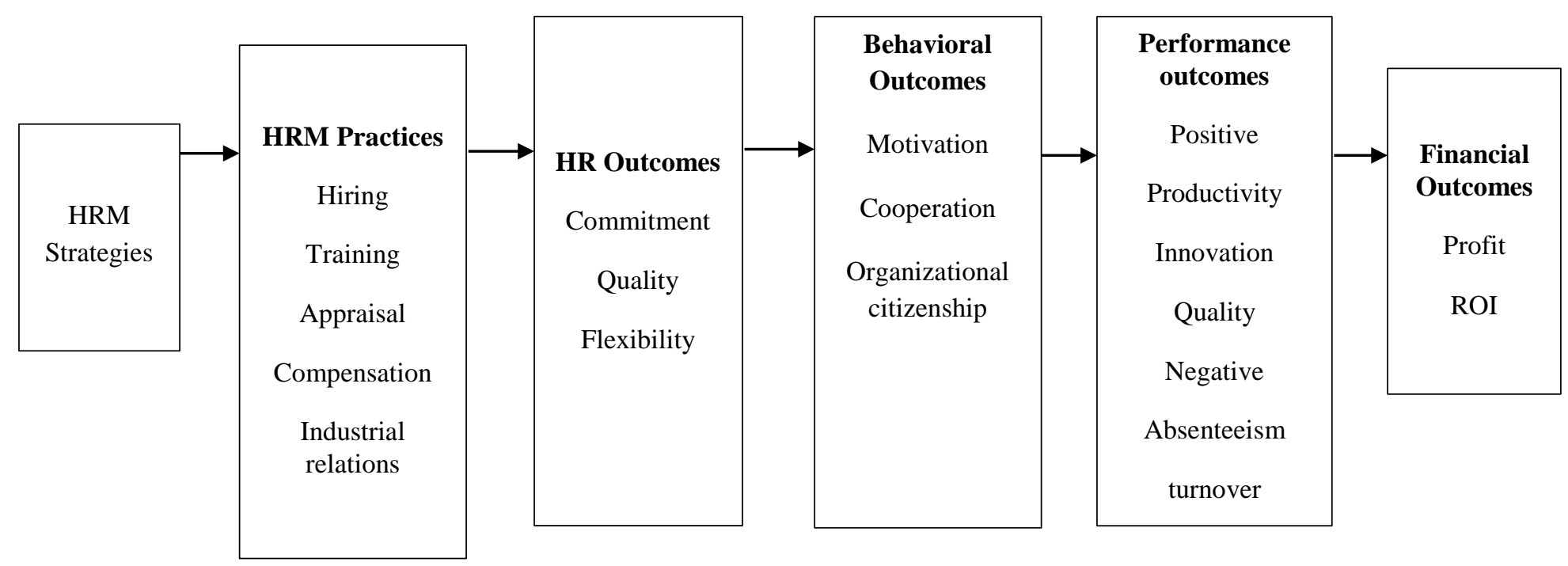

Source: Surendra Jagwan. Models of Human Resource Management. Adapted from: https://professionalshiksha.blogspot.com/2015/10/models-of-human-resource-management.html

This model was proposed by David Guest in 1997. It is based on Human resource management, $4^{\text {th }}$ edition by Alan Price. This model assumed that HR executive initiate activities with some assured policies, which appeal some specific practices and it will come into the conclusions, once it starts implementing. 
These consequences are behavioral performance related and financial rewards. David Guest's $(1989,1997)$ model of HRM stresses the logical classification of six elements:

1. HRM strategy

2. HRM practices

3. HRM outcomes

4. Behavior outcomes

5. Performance outcomes

6. Financial outcomes

This model is based on the assumptions that there is a distinct characteristic of HRM and traditional personnel management and therefore, it is imbedded in strategic management, etc. It is impractical in nature and so, indirectly expresses the conviction that some basic components of HRM system approach for example, commitment have a positive association with the outcomes of an esteemed organization. Guest has recognized that it becomes difficult to establish the relationship between commitment and high performance. Like its American ancestors, this UK model is unitarist i.e., binding employee behavior and commitment into the goals of strategic management and unenthusiastic on the value of trade unions. The employee relationship is viewed as one between the individual and the organization.

\section{Applications of the model:}

The model has extensive applications and has been of the most renowned human resource management models so far. This model is the analytical tool and it allows executives to have an organized and clear understanding of the organization. This model further supports the organisations to have a better understanding of the gaps that prevail in the human resource system and how they can be addressed on time. The model is very clear about the various dimensions that are used in the overall evaluating process of the human resource management.

\section{Limitations of the model:}

The model fails to address to the all human resource management settings. The models need to be generalized so that it is operational at all the levels and can take human resource management measurements from the point of view of customers as well as employees. 


\section{The Warwick Model}

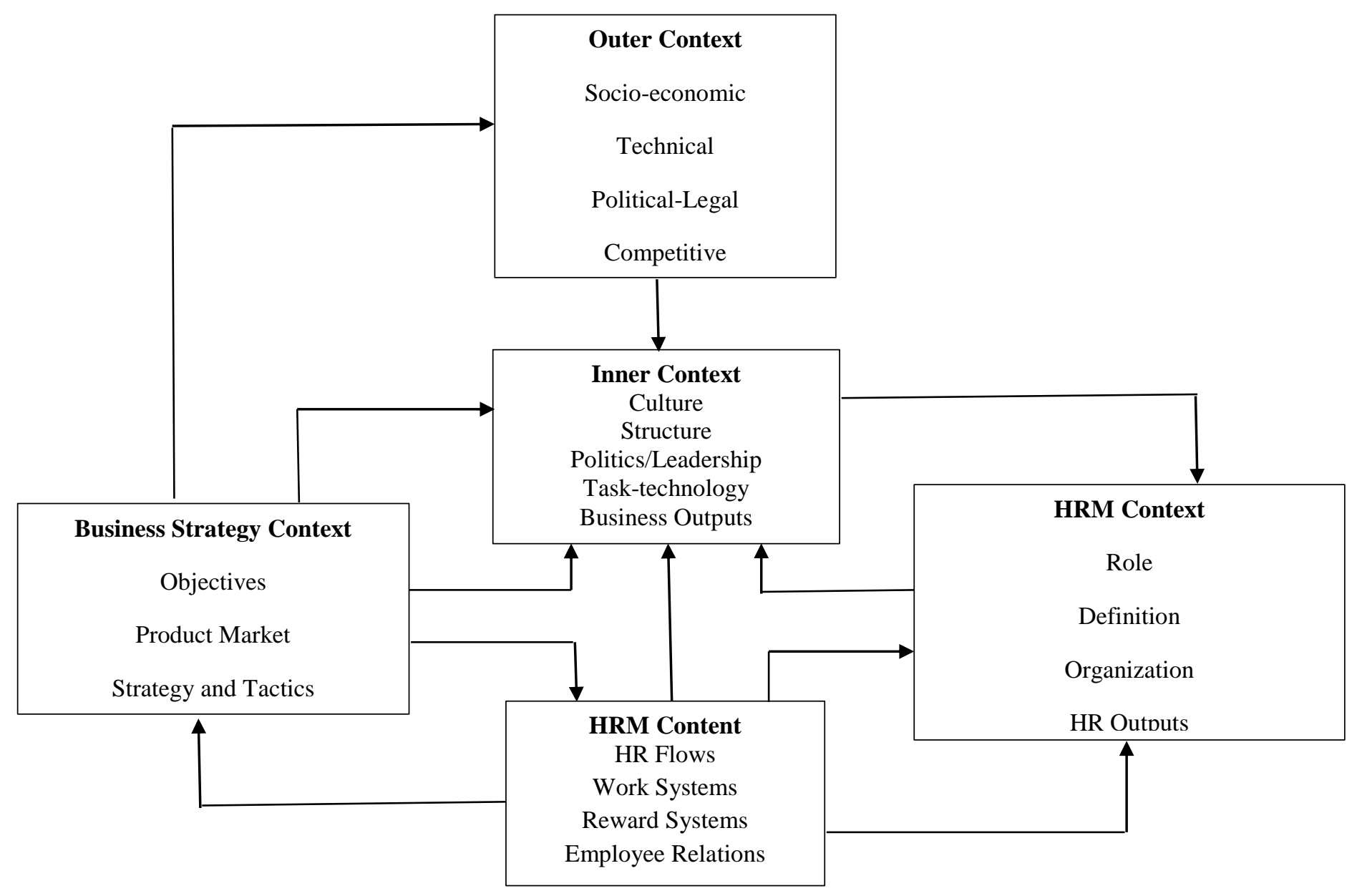

Source: Tangonan (2017). Warwick Model. Adapted from:

https://www.slideshare.net/MaricelTangonan/warwick-model

Two academics in University of Warwick, Hendry and Pettigrew proposed this model. Identical to other models of human resource management, the Warwick theory focuses on five components-

1. Outer context (macro environmental forces)

2. Inner context (micro environmental forces)

3. Organization strategy context

4. HRM context

5. HRM content

Alike the Guest model, the knowledge of business policy and HR practices has been brought into the Warwick model whereas, distinct to the Guest model, these activities arises both in the external and internal environment, and the particular procedure where such alterations occurs, consists of connections between modifications in both context and content. The strong point of the Warwick model is that it recognizes as well as systematizes the effects of major environmental aspects on HRM. It discovers in what way HRM become accustomed to the particular alterations in this framework and also signifies the relationship between the external and environmental aspects. Apparently, the success of the organization depends on how they achieve an alignment between the external and internal environments. 


\section{Applications of the model:}

This model has a tendency to recognize and systematizes the various environmental impacts of HRM. It emphasizes on analytical approach to HRM and mapping the organizational strategy context, identifying the environmental forces, etc.

\section{Limitations of the model:}

The model itself fails to clarify how the human resource management is achieved and operationalized. The model needs falls in the limitation of not providing a clear insight into the various factors that lead to the poor human resource management system.

\section{The Storay Model}

In 1989, John Storay developed the model. This model held that HRM are likely to be more as a human approach than an employment management (soft approach of human resource management). Storay emphasizes more on assurance and human capabilities rather than compliance that what differentiates organizations.

Storay (1989) has characterized 'hard' and 'soft' forms of HRM as:

1. 'Hard' HRM - emphases on the expenses occurred by the employees of an organization.

2. 'Soft' HRM - highlights the 'human' aspects of HRM.

Characteristics of High-Commitment/Soft HRM and Low-Commitment/Hard HRM

\begin{tabular}{|l|l|l|}
\hline CHARACTERISTICS & HIGH-COMMITMENT/SOFT HRM & $\begin{array}{l}\text { LOW-COMMITMENT/HARD } \\
\text { HRM }\end{array}$ \\
\hline EMPLOYER ATTITUDE & $\begin{array}{l}\text { People - focused } \\
\text { Considers HR as biggest assets }\end{array}$ & $\begin{array}{l}\text { Task-focused } \\
\text { Employees employed to do jobs as } \\
\text { directed }\end{array}$ \\
\hline RECRUITMENT & $\begin{array}{l}\text { Based on attitude and integration with the } \\
\text { team }\end{array}$ & $\begin{array}{l}\text { Based on the ability to do the job or to } \\
\text { be trained to do the job in short span } \\
\text { of time }\end{array}$ \\
\hline WOB DESCRIPTION & $\begin{array}{l}\text { High degree of multi-skilling allowing staff } \\
\text { to work in variety of areas }\end{array}$ & Highly defined, with narrow scope \\
\hline $\begin{array}{l}\text { VISIBILITY } \\
\text { CORPORATE GOALS }\end{array}$ & $\begin{array}{l}\text { Continually review work design to be } \\
\text { efficient and enjoyable for staff }\end{array}$ & $\begin{array}{l}\text { Team members understand the bigger } \\
\text { picture } \\
\text { always been done }\end{array}$ \\
\hline $\begin{array}{l}\text { WORKPLACE } \\
\text { CULTURE }\end{array}$ & $\begin{array}{l}\text { Employees on told what they need to } \\
\text { know for the role }\end{array}$ \\
\hline $\begin{array}{l}\text { CAREER } \\
\text { PROGRESSION }\end{array}$ & $\begin{array}{l}\text { Assists employees to plan career and } \\
\text { provides opportunity for employees to } \\
\text { develop within business }\end{array}$ & No progression offered \\
\hline
\end{tabular}

Source: Shabnam. Models of Human Resource Management (HRM). Adapted from: http://www.academia.edu/9821461/u_n_i_t_1_0_models_of_human_resource_management_hrm

The model was based on four components are:

Beliefs -

He believed that human resources ought to be recognized as an important asset. Though, the employees are considered as the most significant factor of production. The success of the organization mainly depends on the spirit of enthusiasm and competences of their workforce.

\section{Strategic qualities -}

The top management of the organization should emphasize more on the HRM strategies, as it is tactical and dynamic in nature. They accept the changes take place in their organizational context. Also, it is considered as the most important source of competitive advantage. 


\section{Role of line managers -}

HRM philosophy has well-defined that importance of HRM and the responsibility of HRM should be assigned to a professional. Therefore, this is clear through the strong connection between the employees and line managers. Line managers performs the roles of HRM on a daily basis.

Key levers -

In this part, the emphasis is on the culture as it is more valuable than processes and systems and it also decreases the chances of disagreements/disputes in an organization, in that way it enhances the power of knowledge and harmony. It also brings concurrence regarding the values, beliefs and assumptions of the organization.

\section{Best Practice Model}

Johnson (2000) notifies HR approaches and systems that influence the organizational performance positively, and in a universal term are regarded as the "best practice" or the "high-performance work practices". Each best HR practices implemented or executed by the organizations will add up to the previous, which increases the resultant organizational performance. The 'best practice' school of HRM is based on the philosophical and theological concept that have universal application or applicability. The premise is that a group of HR practices intended to achieve high commitment or high-performance will promote organizations fully irrespective of this framework.

Pfeffer (1998) has identifies the fundamentals of best practices which are now generally recognized, if not universally known:

1. Employment Security/ Job Security

2. High-level recruitment and selection

3. Team-working and Decentralisation

4. High pays connected to high performance of the organization

5. Comprehensive training and development

6. Narrow Status Differentials

7. Communication and Employee participation

\section{Patterson's Model}

This HRM model declares that HR practices can improve the organizational performance by -

1. Developing intensity and competences of employees

2. Give confidence to the employees to increase positive behavior towards each other and inspiring them to attain their objectives.

3. Best utilization of all resources, particularly human resources.

Therefore, on the basis of these aspects, it is easier to ascertain 'good' or 'high performance' HR practices.

\section{Best Fit Or Contingency Model}

In this model, it is being argued that when HR plans \& policies are connected/fitted to its inclosing framework or nature of their organization, it turns out to be more well-organized and effective. There are 2 elements:

\section{External Fit:}

Under this fit, HR practices are connected to the operations strategy/ marketing strategy i.e., to gain the competitive advantage of the overall organization. According to Schuler and Jackson (1987), it improved the relationship between competitive edge, employee's performance and HRM practices.

\section{Internal Fit:}

HR strategy must be comprehensible. Strategies that are executed in reverse course should be evaded. For instance, fostering joint effort but rewarding individual performance.

\section{Outline to Implement Better HRM}

HR strategy and Business strategy should be line up properly with the help of suitable HR method/assimilation to identify the main connection between them. Additionally, the interests of the employees and aims of the organization should be make parallel with each other in order to avoid conflicts and make proper interaction between them. In another terms, HRM needs to adopt strategic techniques for implementation and increasing the organizational performance, as well achieving the organizational objectives. 


\section{Inferences Of The Study}

This paper has emphasized on the importance and involvement of each model in the HRM. The models have acknowledged various dimensions that have substantial role in the overall development of the human resource. Based on published research it is concluded that HRM practices is a dynamic term and changes or advances with every organization setting, the situation in which it is used and the nature of the top management and employee's performance as well. The research also enlightens HRM practices influence on the performance of employees. All the HRM practices (recruitment \& selection, training \& development, performance appraisal and compensation \& rewards) have been found influencing job satisfaction. It is concluded that human resource management practices act as a most important part of management which has rapidly advanced technologically and helps in the overall enhancement of the organization. The requirement for operative HRM practices cannot be overlooked in the modern organizations. An organization can progress but without the support of its staff, it is less likely to be successful. Having a satisfied staff has become a competitive advantage for organizations as it can ensure that employees provide their best performance which in turn is reflected on the performance of the organization.

\section{References:-}

1. Akram A. J., Ungku N. Ungku A. \& Khalid A. D. (2016). The impact of Human Resource Management practices on employee's performance, International Review of Management and Marketing, 6 (4), 1080-1088.

2. Anya J. (2016). John Storey model of human resource management, Adapted from: https://www.slideshare.net/anyajosephine9/the-storey-model

3. Bontis N. (1999). Managing organizational knowledge by diagnosing intellectual capital: framing and advancing the state of the field, International Journal of Technology Management, Vol. 18 Nos 5-8, 433-62.

4. Delery J. E. (1998). Issues of fit in strategic human resource management: Implications for research, Human Resource Management Review, 8: 289-309.

5. Guest's model of HRM, Adapted from: http://www.hrmguide.co.uk/introduction_to_hrm/guest-hrm.htm.

6. HRM Models, Adapted from: http://www.simplinotes.com/hrm-models/.

7. Ihtifaz (2014), Adapted from: https://www.slideshare.net/Nordis512/mhr-16

8. Jaskiene J., Buciuniene I. (2015) HRM Practices and Research Performance Linkage in Higher Education Context, 9th Biennial International Conference of the Dutch HRM Network "Recontextualizing HRM". Utrecht, 12(13), 1-18.

9. Jones, J. J., \& Walters, D. L. (1994). Human resource management in education, Technomic.

10. Legge, K. (1995). Human Resource Management, Rhetorics and Reality (Macmillan, London).

11. Maricel G. Tangonan (2017). Warwick Model. Adapted from: https://www.slideshare.net/MaricelTangonan/warwick-model.

12. Mohamed Sabry. Models of Human Resource Management, Adapted from: https://mohamedsabry.com/blog/models-of-human-resource-management/.

13. Neha (2015). HR Knowledge, Adapted from: http://nehaspeakshr.blogspot.com/

14. Preeti (2017). HRM Models, Adapted from: http://www.simplynotes.in/ uncategorized/hrm-models/.

15. Schuler R.S., Jackson, S.E. (1987). Linking competitive strategy with human resource management practices, The Academy of Management Executive (1987-1989), 207-219.

16. Shabnam. Models of Human Resource Management (HRM), Adapted from: http://www.academia.edu/9821461/u_n_i_t_1_0_models_of_human_resource_management_hrm.

17. Kukreja S. (2013). Human Resource Management Models, Adapted from: https://www.managementstudyhq.com/hrm-models.html

18. Jagwan S. (2015). Models of Human Resource Management, Adapted from: https://professionalshiksha.blogspot.com/2015/10/models-of-human-resource-management.html

19. Tyson S. (1997). Strategic prospects for HRM, Institute of personnel and development IPD House Camp road

20. Tzafri. \& Gur (2007). HRM Practices and Perceived Service Quality: The Role of Trust as a Mediator. Research $\&$ Practice in Human Resource Management, 15(2). 